\title{
Imperialism, research ethics and global health
}

\author{
Solomon R Benatar University of Cape Town and Groote Schuur Hospital, Observatory, South Africa
}

The ongoing debate on the ethics of studies involving rich and poor countries ${ }^{1-4}$ is to be welcomed, for several overlapping reasons: first, to develop a deeper understanding of the complexity of the issues under consideration; second to examine more broadly the concept of imperialism in this context, and third, to seek to improve global health through processes that go beyond simplistic band-aid or self-serving approaches.

It is widely recognised (although perhaps less openly acknowledged than is desirable) that research, even under the best of circumstances, is potentially exploitative. ${ }^{5}$ Because "powerful researchers" (individuals and corporations) usually have more to gain than any single research participant, much effort over recent decades has gone into designing protection for research subjects. That most of this protection lies at the level of requirements for the design and review of research protocols and very little at the level of what actually happens in the conduct of research reflects some or all of the following: (i) acceptance that researchers will do what they say they will do; (ii) a willingness to believe that informed consent in practice meets up to its moral rather than its legal requirements, or to ignore that it does not; (iii) confidence that conflicts of interest can be eliminated, and (iv) that the desire to achieve protection may have a lower priority than the pursuit of knowledge. These shortcomings of the protection process allow potentially exploitative research to continue even within perfectly designed and ethically approved studies. Seen against this background Angell's powerfully expressed concern for preventing exploitation is admirable. ${ }^{2}$

However, her critique of the HIV transmission studies under question is diminished in at least two ways, first by stating that the Declaration of Helsinki "requires [my italics] control groups to receive the 'best' current treatment...". The precise wording of the declaration is: "The potential benefits, hazards and discomfort of a new method should be weighed against the advantages of the best proven diagnostic and therapeutic method," and: "In any medical study, every patient - including those of a control group, if any - should be assured of the best proven diagnostic and therapeutic method" [my italics]. For the studies referred to, the requirement to weigh benefits and hazards demands that attention be given to whether the AZT regimen was necessarily the best proven method for a population of women and infants differing from those studied in France and the US, and living in a context where, for economic and logistic reasons the goals of treatment may have to be less ambitious. In particular it is necessary to question whether preventing breast feeding as part of the research protocol is justifiable in Africa, given the direct risks for infants in such an environment and the indirect risks from the possibility of an early next pregnancy. It seems somewhat imperialistic to presume that a drug regimen shown to be of value in some of the wealthiest countries in the world is necessarily the best proven regimen for some of the poorest. While it may be, it may also not be. Reasons provided for designing studies to produce most efficiently results more directly relevant to the local situation ${ }^{4}$ indicate that a greater degree of complexity in planning and executing such research is required than is acknowledged by Angell.

Second, by drawing an analogy with the Tuskegee experiments, Angell minimises the deception, maleficence, paternalism, lack of accountability, racism, and crass exploitation demonstrated by the researchers and those colleagues who knew, but remained silent, about the study. Lurie and Wolfe also draw some implausible analogies. ${ }^{1}$ The syphilis experiment in the US, following in the wake of the Nuremberg trials and promulgation of the Nuremberg Code, surely cannot be trivialised by comparing it with a study that had been discussed, reviewed and accepted by national and international groups (which included thoughtful bioethicists) or with attempts to diminish exploitation by involving in-country health workers in the design of studies. While these procedures may not totally eliminate exploitation, they are nevertheless 
aspects that have been underplayed by Angell. Ethical dilemmas, by their very nature, are often not amenable to solutions which can be shown to be unequivocally substantively correct, hence the importance of appropriate and accountable procedural mechanisms for making ethical decisions. The Tuskegee study did not remotely approach the level of ethical awareness or procedural probity associated with the HIV transmission studies.

It is also necessary to be critical of simple assertions about what is ethical, especially when these are inconsistent with the actions of the protagonist. For example a recent Lancet editorial took a strong and somewhat dogmatic stand against the placebocontrolled HIV transmission studies, ${ }^{6}$ having two weeks previously published a randomised placebo control trial on elderly patients with isolated systolic hypertension ${ }^{7}$ - despite the fact that by 1991 it had been established that the standard treatment for such patients was diuretics. ${ }^{8}$ Such inconsistency undermines credibility.

However, much more important issues are at stake. A recent publication from the Institute of Medicine stated that: "America has a vital and direct stake in the health of people around the globe, and this interest derives from both America's long and enduring tradition of humanitarian concern and compelling reasons of enlightened self-interest" [my italics]. ${ }^{9}$ The balance of these concerns is reflected in the priorities given to expenditure in the US: $15 \%$ of Gross National Product (GNP) on health care in the US $(\$ 3,500$ per American per year), $4 \%$ of GNP on the military (more than any other nation) and $0.1 \%$ of GNP on foreign assistance (less than all OECD countries - of which Denmark is the largest donor at $0.97 \%$ of GNP and Italy the second smallest at $0.14 \%$ of GNP). In a poll conducted in January 1995 by the Program on International Policy Attitudes at Maryland University, the median level of proposed foreign aid by those polled was 15 times greater than the amount actually spent. ${ }^{9}$ This reveals the gap between concern expressed for the wellbeing of distant others and its translation into practice. The clear need for new approaches to foreign aid and global health is emphasised by the fact that $50 \%$ of the world's population live on less than $\$ 350$ per person per year, for reasons not insignificantly related to the exploitative economic and political policies of powerful nations. ${ }^{1011}$

Seen in this context Angell's concern about exploitation is thus of great importance. It draws attention to the need for concern about exploitation in medical research to be seen in the context of the exploitative milieu in which modern medicine is practised. ${ }^{5}$ Careful examination of the powerful economic and political forces which increasingly polarise people into poor and rich, within amd between nations, reveals (i) the extent to whigeh privileged people worldwide take their standardiof life and their desire for continuous economic growth for granted (regardless of the cost to othess) and (ii) how they are unwittingly co-opted ito exploitative and often imperialistic processes. ${ }^{2}{ }^{13}$ While such imperialism differs markedly frōm imperialism in the age of empire it retains a supremacist component. ${ }^{11}$ In a globalising world understanding these issues is crucial to addressing the concept of national and global health - regagedless of location or wealth. Because much of record of aid to poor countries is tainted by exp而itation, as powerfully illustrated by Hancock did others, ${ }^{14}$ Angell is lauded for expressing great concern for patients in distant and poor countries, fad for striving to prevent even benevolent aid effort $\overrightarrow{\text { in }}$ medical research from becoming thinly disguised forms of exploitation. Her concern, if redirected into broader efforts to reshape public opinion political will in rich nations, could have profounglly beneficial effects on global health.

Solomon R Benatar MB, ChB, FFA (SA), FR\&Ë is Professor of Medicine and Head of The Departn Medicine and The Centre for Bioethics, Univer Cape Town and Groote Schuur Hospital, Obsrgatory, Cape, South Africa.

\section{References}

1 Lurie P, Wolfe SM. Unethical trials of interventions to re $\overrightarrow{\bar{\Phi}}$ perinatal transmission of the Human Immunodeficiency Vitus in developing countries. New England fournal of Medioine 1997:337:853-56

2 Angell $M$. The ethics of clinical research in the third world. New England fournal of Medicine 1997:337: 847-49.

3 Msamanga GI, Fawzi WW. The double burden of 夏IV infection and tuberculosis in sub-Saharan Africa. New England fournal of Medicine 1997:337:849-51.

4 Varmus H, Satcher D. Ethical complexities of conducing research in developing countries. New England fournabs of Medicine 1997:337:1003-5.

5 Spece RG, Shimm DS, Buchanan AE. Conflicts of interes in clinical practice and research. New York: Oxford University Perss, 1996.

6 Anonymous [editorial]. The ethics industry. Lancet 1997;950: 897.

7 Staessen JA et al. Randomised double-blind comparison of cebo and active treatment for older patients with isolated systolic hypertension. Lancet 1997;250:757-64.

8 SHEP co-operative research group. Prevention of strokfuby antihypertensive drug treatment in older persons with isoled systolic hypertension: final results of the systolic hyperter Sfon $^{2}$ in the elderly program. Fournal of the American Medical A $\underbrace{}_{\text {foci- }}$
ation 1991;265:3255-64.

9 Institute of Medicine. America's vital interest in global heolth. Washington DC: National Academy Press, 1997.

10 Pettifor A. Debt, the most potent form of slavery. London: Rebt $_{\text {ebr }}$ Crisis Network, clo Christian Aid Society, 1995.

11 George S, Sabelli F. Faith and credit: the World Bank's secolar empire. London: Penguin, 1994.

12 Benatar SR. Global disparities in health and human rights. American Fournal of Public Health 1998;88:295-300.

13 Benatar SR. WHO report 1996: some millennial challeag es. fournal of the Royal College of Physicians of London. 1997;31:\$565 .

14 Hancock G. Lords of poverty. London: Mandarin, 1989. 